Discussion Paper No. 813

\title{
ASKING ABOUT CHANGES IN HAPPINESS IN A DAILY WEB SURVEY
}

\author{
Yoshiro Tsutsui \\ Fumio Ohtake
}

July 2011

The Institute of Social and Economic Research Osaka University

6-1 Mihogaoka, Ibaraki, Osaka 567-0047, Japan 


\title{
Asking about changes in happiness in a daily web survey
}

\author{
Yoshiro Tsutsui (Osaka University) \\ and \\ Fumio Ohtake (Osaka University)
}

\begin{abstract}
This paper investigates whether the level of happiness and integrated process of changes in happiness are the same. Using the daily data of two waves of four and six months each, we found that the level of happiness is stationary, whereas the integrated process of changes is non-stationary with a rising trend, implying that they are different series. An examination of the causes of the difference indicated that although adaptation completely influences the level of happiness, it only partially influences the change in happiness. This may be because the latter is based on a comparison between today and yesterday,.
\end{abstract}

JEL Classification Numbers: I31

Keywords: change in happiness, Easterlin paradox, daily web survey, adaptation 


\section{Introduction}

In recent years, the economics of happiness, which is defined as the research area that uses data on subjective happiness, has experienced significant development (Frey and Stutzer, 2002a, b; Bruni and Porta, 2005; Dolan et al., 2008). However, no agreement has been reached regarding whether subjective happiness is actually comparable between people. Moreover, we do not completely understand how subjective happiness relates to utility. ${ }^{1}$ Thus, the economics of happiness is still at the stage where the validity of analyses that use subjective happiness is still being examined and the relationship between subjective happiness and utility is still being investigated.

The Easterlin paradox that average happiness in a country is stable at a constant level for a long period, while the country's GDP grows substantially is an interesting phenomenon from the perspective of considering the validity of the use of happiness data (Easterlin, 1974; Clark et al., 2008). ${ }^{2}$ This paradox suggests that economic growth is meaningless if greater happiness is the goal (Frank, 2005). This conclusion radically contradicts ordinary intuition and common sense. In comparison, higher income is expected to result in higher utility because utility is defined on the basis of a comparison between two states; no one would choose a life with lower

${ }^{1}$ Kimball and Willis (2006) theoretically examined the relationship between them. ${ }^{2}$ Stevenson and Wolfers (2008) questioned the existence of the paradox in Japan and the EU. 
income, other things being equal. Utility differs from subjective happiness in this regard.

This paper proposes a new type of question for tracking subjective happiness. ${ }^{3}$ Instead of asking about the level of happiness, which is the approach that was adopted by most of the previous surveys, we ask about the change in the level of happiness from the previous day using a daily web survey. Integrating the changes in happiness and adding the level of happiness of the first date, we reconstruct the level of happiness. The calculated level of happiness ought to coincide with the data of the level of happiness obtained directly using the web survey. If they do in fact coincide, asking regarding the change in happiness is pointless. However, the two series might be completely different, because in order to answer the question on changes in happiness, respondents need to compare today's state with yesterday's state. The answer to the question on changes in happiness and utility bear similar aspects in that both are based on a comparison.

If we find that the level of happiness and the integrated process of changes in happiness differ, then we will investigate the cause of the divergence. Our speculation is as follows: one of the causes of the Easterlin paradox is that people soon adapt to a new level of happiness. This implies that people becomes happier with an increase in income in the short-run; however, in

\footnotetext{
${ }^{3}$ Regarding developments in the measurement of subjective happiness, refer to Kahneman and Kruger (2006).
} 
the long-run, a part of the increase in happiness is cancelled by adaptation (Easterlin, 2005; Di Tella et al., 2007; Clark et al., 2008). ${ }^{4}$ Nevertheless, a change in happiness, like a change in utility, may not be significantly affected by adaptation because it is based on a comparison between today's state and yesterday's state. Under this supposition, this paper examines how the level of happiness and a change in happiness are affected by adaptation. If it is found that adaptation affects the level of happiness more than change in happiness, the integrated process of the change in subjective happiness may be a closer variable to utility than the level of happiness.

The remainder of the paper is organized as follows. Section 2 explains our daily survey, which includes questions on the level of happiness and on the daily change in happiness. Section 3 analyzes whether the integrated process of the changes in happiness differs from the level of happiness. Given the result that the series differ, Section 4 investigates three possible reasons for the difference. Section 5 discusses the implications of the obtained results to the Easterlin paradox and concludes the paper.

\section{The daily survey}

\footnotetext{
${ }^{4}$ Another cause of the Easterlin paradox is that people evaluate their happiness in comparison with others' situations. This is called the relative income hypothesis (Duesenberry, 1949; Clark and Oswald, 1996; Clark et al., 2008); however, this paper does not focus on this hypothesis.
} 


\section{$\underline{\text { Two waves }}$}

We solicited undergraduate and graduate students at Osaka University and requested them to report their happiness every day for several months. ${ }^{5}$ They responded using their personal computers and mobile phones. ${ }^{6}$ To the best of our knowledge, administering a daily survey like this for a long period of time is unique to this study. The survey enables us to estimate a happiness function with panel data, which has the merit of excluding the difference in happiness between people with a fixed (or random) effect model. In other words, it enables us to estimate a within-subjects happiness function, which is immune to a direct comparison of subjective happiness between people.

Our daily survey consisted of two waves. The first (2008-survey) was from December 1, 2007 to March 31, 2008, and the number of respondents decreased slightly during this period from 68 to $64 .^{7}$ The second wave (2009-survey) was from January 1 to June 30, 2009. During this period, the number of respondents decreased from 52 to $41 .^{8}$

\footnotetext{
${ }^{5}$ We also asked questions including valuations of personal and macro news (how good or bad they were) arriving on that day, as explained below.

${ }^{6}$ Most younger residents of Japan carry mobile phones that have the capability of connecting to the Internet and sending emails.

${ }^{7}$ The first wave started in November 1, 2006. However, the survey did not include a question on changes in happiness until December 2007.

${ }^{8}$ The second phase was initially planned to conclude at the end of March; however, it was extended
} 
$\underline{\text { Questions and definition of variables }}$

In the survey, we asked 13 questions; here, we explain those questions that were used in the analysis in the current paper. $^{9}$

Q1. How happy are you now?

Choose a number between 0 and 10.0 is "very unhappy," 10 is "very happy."

$\begin{array}{lllllllllll}10 & 9 & 8 & 7 & 6 & 5 & 4 & 3 & 2 & 1 & 0\end{array}$

$L E V E L$ is defined as the answer, which represents the level of happiness on a scale from 0 to 10.

Q5. Recall the most important personal news or event that occurred since you answered this questionnaire yesterday. How did you evaluate the news?

Choose a number between -5 and 5.5 is "very good," -5 is "very bad."

$$
\begin{array}{lllllllllll}
-5 & -4 & -3 & -2 & -1 & 0 & 1 & 2 & 3 & 4 & 5
\end{array}
$$

$P \_N E W S$ is defined as the answer, which represents the rating of the importance of the personal news that the respondent received that day.

until the end of June. This is the reason why the number of respondents decreased substantially. In fact, the number of respondents decreased from 47 in March to 41 in April.

${ }^{9}$ Questions 2, 3, 4, 6, and 8 are not used in this paper; therefore, we have omitted their explanation. 
Q7. Recall the most important news that was in the newspaper or on TV since you answered this questionnaire yesterday. How did you evaluate the news?

Choose a number between -5 and 5.5 is "very good," -5 is "very bad."

$\begin{array}{lllllllllll}-5 & -4 & -3 & -2 & -1 & 0 & 1 & 2 & 3 & 4 & 5\end{array}$

$M \_N E W S$ is defined as the answer, which represents the rating of the macro news that appeared on TV and/or in newspapers that day.

Q9. Did you sleep well last night?

1. poor sleep, 2 . slightly poor sleep, 3. slept well, 4 . slept very well

SLEEP is defined as the answer, which represents the quality of sleep. A larger number means better sleep.

Q10. How is your health now?

1. good, 2. generally good, 3. generally not good, 4. bad

HEALTH is defined as four minus the answer to Q10, which represents the quality of health. A larger number means better health.

Q11. Do you feel any anxiety and stress now? 
1. a lot, 2. a little, 3. not much, 4. none

NOANXIETY is defined as the answer, which represents the level of anxiety and stress. A larger number means less stress.

Q12: Have you already attended a class today or are you going to attend a class today?

1. I have attended a class, 2 . I will be attending a class, 3. I am attending a class now, 4.

No class today

We define NOCLASS as 1 if the respondent has no class today, and 0 otherwise

Q13: Your happiness today compared with your happiness yesterday (before) is

1. much happier, 2. reasonably happier, 3. slightly happier, 4. same as yesterday (before),

5. slightly unhappier, 6. reasonably unhappier, 7. much unhappier

We define CHANGE as four minus the answer to Q13, which represents change in happiness from yesterday (or the time when they answered the last survey) and ranges from -3 (much unhappier) to 3 (much happier).

We present descriptive statistics of these variables for both waves in Table 1. In 2008-survey, the mean of $L E V E L$ is 5.8, which is relatively lower than the level of happiness, 6.4, reported in "Kokumin Seikatsu Senkodo Chosa" (Survey on preferences in life of nations; 
webpage of the Cabinet Office). The mean of CHANGE is positive, implying that the respondents were becoming happier during the observed period. The mean of $P_{-} N E W S$ is slightly positive, implying that overall, they received good news, which is consistent with the fact that the mean of $C H A N G E$ is positive. In contrast, $M \_N E W S$ is slightly negative, which implies that overall, the macro news was bad. SLEEP and HEALTH are larger than 2.5, that is, the average on the scale of 1 to 4 , suggesting that overall, respondents were in good health and slept well. However, the mean of NOANXIETY is smaller than the average on the scale of 1 to 4 , suggesting that the average respondent was bothered by stress and anxiety. The mean of NOCLASS is $0.68 .^{10}$

The values of the variables of 2009-survey are not radically different from those of 2008-survey. However, the values of LEVEL, CHANGE, and P_NEWS in the 2009-survey were larger than those of the corresponding variables in the 2008-survey, thereby suggesting that the respondents of 2009-survey were happier than those of 2008-survey.

${ }^{10}$ Since Osaka University has 26 school days from January 1 to March 31 (there is a spring vacation in February and March), this number implies that respondents attended most of the school days and responded to the questionnaire. In 2009-survey, the mean of NOCLASS is 0.58 , implying that they attended classes for approximately 76 days out of the 81 school days from January to June. However, "Class" in the question includes experiments at laboratories in natural science and technology departments, which are conducted on days when school is not in session. Therefore, the above assessment is crude. 


\section{$\underline{\text { Rewards }}$}

Respondents were requested to connect to the webpage and to answer the questions every day.

They were paid 160 yen per answer for the daily survey. Those who responded to the daily survey for over 22 days and those who answered the hourly survey more than once a month were paid 1,300 yen as a bonus for the month, and those who responded to the daily survey for over 27 days and answered the hourly survey received 2,600 yen as a monthly bonus. ${ }^{11}$

\section{$\underline{\text { Response rate }}$}

Figure 1 shows the response rate of the daily survey for each month. In both 2008- and 2009surveys, the response rate is approximately $90 \%$.

3. Comparison between the level of happiness and the integrated process of the change in happiness

${ }^{11}$ In the web survey, respondents were also requested to report their hourly happiness on one day of their choice each month. We call this the hourly survey. The hourly survey essentially follows an experience sampling method (Csikszentmihalyi and Hunter, 2003; Scollon et al., 2003), which is better than Kahneman et al.'s (2004 a, b) day reconstruction method, wherein respondents answer questions in real time, so that the responses are immune to memory biases. We do not explain the hourly survey in detail because we do not use the results in the current paper. 


\subsection{Comparison of the averaged data}

In this section, we check if the two series of happiness, LEVEL (Q1; level of happiness) and CHANGE (Q13; change in happiness) are consistent with each other. To this aim, we define the following two variables associated with LEVEL and CHANGE.

DIFFERENCE: the difference in LEVEL from the day before

INTEG: the sum of the LEVEL on the first day and CHANGE of the consecutive days until the current day

Table 1 presents the descriptive statistics of INTEG and DIFFERENCE. INTEG widely ranged from -151 to 347 in the 2008-survey and from -167 to 476 in the 2009-survey. DIFFERENCE was very small in both the surveys and was not statistically different from zero.

Aside from the scaling of CHANGE in its definition, by mathematical definition, DIFFERENCE and CHANGE (and therefore, LEVEL and INTEG) should follow the same series. In order to check if they are in fact the same, we calculate the average of these four variables over respondents for each day. Specifically, we calculate INTEG by calculating the integrated process of each respondent, and then averaging them. ${ }^{12}$ In Figure 2, the averages of LEVEL and

\footnotetext{
${ }^{12}$ Alternatively, we can first average CHANGE over respondents each day and then construct an integrated process of these averages. INTEG constructed in this way is smoother than that in Figure 2, and it does not show an increase in volatility. This is because averaging CHANGE over respondents makes the variance much smaller (i.e., the variance is denominated by the number of
} 
INTEG are presented for the two waves. It is apparent that although LEVEL is stabilized at a constant level in both phases, INTEG grows throughout the periods. ${ }^{13}$ INTEG also shows growing volatility throughout the periods. ${ }^{14}$ Thus, the figure reveals that the two series are completely different.

In Figure 3, we show CHANGE and DIFFERENCE. The figure reveals that although DIFFERENCE is positive and negative with similar probability, CHANGE is more frequently positive than negative. In fact, the hypothesis of the same mean for CHANGE and DIFFERENCE is rejected at the $1 \%$ level in both the waves. Although the mean of CHANGE is significantly positive, that of DIFFERENCE is not significantly different from zero (see Table 1).

\subsection{Panel unit root tests}

Figure 2 gives us the impression that LEVEL is a stationary series, whereas INTEG is non-stationary. If this is the case, the two series are certainly different. In order to check this, we respondents). However, it increases with time as in Figure 2, so that the essential conclusions are unaltered. See footnote 14.

${ }^{13}$ Comparing INTEG of the two phases, we found that the one in 2009-survey grows more rapidly: in the 2008-survey, it reaches 20 in four months, whereas in 2009-survey it reaches 40 in six months. ${ }^{14}$ This is because the disturbance term of the integrated process of an individual increases in proportion with time; therefore, its variance increases in the quadratic function of time. 
conduct panel unit root tests for the four series LEVEL, INTEG, CHANGE, and DIFFERENCE for the two waves.

Specifically, we employ pooled tests based on Fisher's type statistic, as defined in Choi (2001). Choi's (2001) test combines p-values from a unit root test applied to each individual under the null hypothesis that all cross section units have a unit root, against the alternative that some of the panel units are stationary. Choi's (2001) test statistic, termed $P_{\mathrm{N}}$ statistic in this paper, is as follows:

$$
P_{\mathrm{N}}=\frac{1}{2 \sqrt{\mathrm{N}}} \sum_{i=1}^{N}\left(-2 \ln p_{\mathrm{i}}-2\right) \rightarrow N(0,1), \quad \text { as } T \rightarrow \infty, N \rightarrow \infty,
$$

where $p_{i}$ is the $p$-value associated with the unit root test statistic for individual $i$. We use two types of unit root tests: the Augmented Dickey-Fuller (ADF) test where the null hypothesis is a unit root (Dickey and Fuller, 1979) and the Kwiatkowsk-Phillips-Schmidt-Shin (KPSS) test where the null hypothesis is stationarity (Kwiatkowski et al., 1992). Because the power of the tests of the unit root null is low in small samples, testing the stationarity null is indispensable. We examine two specifications: "with constant" and "with constant and time trend (TREND)."

Table 2 presents the test results. ${ }^{15}$ The upper panel shows the results of 2008-survey. In the two specifications, with or without TREND, the results are almost identical. As for LEVEL,

15 The number of lags of the lagged difference terms of the ADF test is selected according to Akaike information criterion (AIC) for each regression. The number of lags truncation in the KPSS tests is set at 12 . 
DIFFERENCE, and CHANGE, the ADF test rejects the null of non-stationarity, and the KPSS test accepts the null of stationarity, suggesting that these series follow a stationary process. On the other hand, as for INTEG, the ADF test accepts the null of non-stationarity, and the KPSS test rejects the null of stationarity, suggesting that the series is non-stationary. The same results are obtained for the 2009-survey, and they are shown in the lower panel. Thus, the results unequivocally indicate that INTEG is non-stationary, whereas the other variables are stationary, implying that $L E V E L$ and INTEG cannot be the same series.

As for CHANGE and DIFFERENCE, although both series are stationary, the mean of CHANGE is significantly positive, whereas that of DIFFERENCE is not significantly different from zero. In addition, their correlation coefficient is only 0.456 in 2008 and 0.417 in 2009. These results suggest that they are not the same series, even if they have some relationship.

In summary, the results of the unit root tests indicate that $L E V E L$ and INTEG cannot be the same series. This also applies to CHANGE and DIFFERENCE.

4. Why are the two series different?

Mathematically, the results of the integrated process of CHANGE must be identical to the level itself. Thus, we need to question why the two series differ. We suggest and examine three possible reasons for this. 


\subsection{Loss aversion}

Asking a question regarding the change in happiness forces respondents to measure their happiness using the level of yesterday's happiness as the reference point. Thus, loss aversion, by which a loss is evaluated as having twice the weight of a gain, may somehow affect the results (Kahneman and Tversky, 1979; Tversky and Kahneman, 1992).

However, since CHANGE and LEVEL themselves are the evaluation of good and bad states, loss aversion would not explain the gap between CHANGE and DIFFERENCE or between $L E V E L$ and INTEG.

The result that CHANGE tends to be positive simply implies that there are more good aspects so as to make CHANGE positive even after the evaluation owing to loss aversion. ${ }^{16}$ Indeed, since overall, our subjects get good news, maintain good health, and get good sleep (see Table 1), it is not surprising that they tend to become happier.

\subsection{Asking about happiness within a certain range}

The second possibility arises from the style of the question that investigates the level of 16If good and bad events happen randomly with 50\% probability each, and if subjects assign greater weight to bad events, the change in happiness tends to be negative, which contradicts our results. 
happiness on a range from 0 (very unhappy) to 10 (very happy). Assume that the level of happiness is linearly increasing with time similarly to INTEG. In this case, respondents cannot report their actual level of happiness because the answer is limited by an upper bound of 10 . Therefore, they may report their level of happiness by transforming the linear function to a function that is asymptotic to 10 and 0 as the level of original happiness goes to infinity and minus infinity, respectively. An example of such a function is the logistic function:

$$
H=L+\frac{U-L}{1+\exp (-r \widetilde{H})},
$$

where $H$ is the reported level of happiness, $\widetilde{H}$ is the original level of happiness, $U$ and $L$ are the upper and lower limits, respectively, and $r$ is a parameter determining the slope of the function. By a simple calculation, we can recover $\widetilde{H}$ from $H$ with the inverse function of (2), which is called the logit function:

$$
\widetilde{H}=\frac{1}{r}(\ln (H-L)-\ln (U-H)) .
$$

Let us examine whether the recovered series $\widetilde{H}$ using Equation (3) resembles INTEG. Specifically, we set $U=10, L=0$, and $r=0.1$, and first calculate $\widetilde{H}$ for each respondent using Equation (3) and then average them. ${ }^{17}$ The recovered $\widetilde{H}$ using the actual values of $H$ is depicted in Figure $4 .{ }^{18}$ As shown in the figure, $\widetilde{H}$ is a kind of enlarged figure of LEVEL in ${ }^{17}$ Here, $r$ is chosen arbitrarily.

${ }^{18}$ Alternatively, we can use average $H$ over respondents to calculate $\widetilde{H}$ with Equation (3). The results are similar to the graph in Figure 4; thus, the calculated $\widetilde{H}$ is not increasing and does not 
both waves, and does not increase with time as INTEG does. ${ }^{19}$

Thus, the supposition that asking about happiness in a certain range is the cause of the gap between LEVEL and INTEG is invalid. This result is consistent with our intuition, because LEVEL in Figure 2 fluctuates around a constant level and does not show an increasing trend. A transformation using Equation (3) simply extends the form; therefore, it cannot be expected that a constant series will be transformed into an increasing function.

However, one may argue that the transformation using Equation (3) is biased because the extension of $H$ is symmetrical around $H=5$ in spite of the fact that the average of $H$ is approximately 6 . Therefore the region below $H=6$ should be extended more intensively compared with the region above $H=6$. If this is done, then the result may change. In order to address this concern, we estimate an ordered probit model of $H$ in order to obtain the estimates of the cutoff values of 0 to 10 . Then, we calculate the expected value of each class by fitting a standardized normal distribution to the actual frequencies falling in these classes. These estimates represent "standardized latent happiness," which corresponds to $\widetilde{H}$ in Equation (3). The latent happiness thus calculated is depicted in Figure $5 .^{20}$ It is apparent from the figure that resemble $L E V E L$ either.

${ }^{19}$ We also depict the case of $U=7.5, L=5.5$, and $r=0.02$. The graph is extended more; however, it does not show an increasing trend.

${ }^{20}$ In the figure, latent happiness is multiplied by 10 because the variation is too small to be observed 
these estimates do not show an upward trend. Thus, the conclusion that asking about happiness

in a certain range is not the cause of the difference is confirmed.

\subsection{Adaptation}

The last possibility examined in this paper is that although LEVEL (and therefore, DIFFERENCE) is affected by adaptation, CHANGE (and therefore INTEG) is not.

Although our respondents tend to become happier every day because of, for example, the receipt of good personal news, they may adapt themselves to the happier situation brought about by the good news and return to their original level of happiness in a few days. We speculate that CHANGE is less affected by adaptation than DIFFERENCE. In this subsection, we compare CHANGE and DIFFERENCE, rather than INTEG and LEVEL, because we conduct a regression analysis, which requires that the variables be stationary.

In our questionnaire, variables that may affect the respondents' happiness are $P \_N E W S$, M_NEWS, SLEEP, HEALTH, NOANXIETY, and NOCLASS. We regress CHANGE and DIFFERENCE over these variables and their lagged variables and check whether the lagged variables have opposite effects on happiness to those of the current variables. If the lagged variables have opposite effects to those of the current ones, the effect of the current variables is

otherwise. 
cancelled, at least partially, in the consecutive periods (Clark et al., 2008). For the exposition, assume that happiness, $H$, depends on $P \_N E W S$ for four periods such that

$$
\mathrm{H}_{\mathrm{t}}=\text { constant }+\alpha \mathrm{P}_{-} \mathrm{NEWS}_{\mathrm{t}}-\sum_{\mathrm{i}=1}^{3} \beta_{\mathrm{i}} \mathrm{P}_{-} \mathrm{NEWS}_{\mathrm{t}-\mathrm{i}}+\mathrm{u}_{\mathrm{t}}, \quad \alpha, \beta_{\mathrm{i}}>0 .
$$

Then, a one-unit increase in $P_{-} N E W S$ raises happiness by $\alpha$ units in the short-run (the current day); however, it raises happiness by only $\alpha-\sum_{\mathrm{i}=1}^{3} \beta_{\mathrm{i}}$ units in the long-run (three days later). If our respondents adapt to the news, such a result will be obtained by the regression of Equation (4).

Table 3 presents the results for 2008- and 2009-surveys estimated by random or fixed effect models. ${ }^{21}$ Since the two results are essentially similar, we only explain the results for the 2009-survey (lower panel) in order to save space. The results are summarized in the following four points.

First, the coefficients of the current variables show the expected positive signs for most cases. In particular, $P \_N E W S, H E A L T H$, and NOANXIETY have large effects on happiness.

Second, regarding the current variables, the magnitudes of the estimates are similar for CHANGE and DIFFERENCE for all the variables except SLEEP and NOCLASS.

Third, focusing on the significant estimates, the estimates of the current variables and those of the lagged variables take the opposite signs for $P \_N E W S, M \_N E W S, H E A L T H$, and

${ }^{21}$ We selected the model based on the Hausman test. 
NOANXIETY. These results imply that the long-run effect of these variables on happiness (CHANGE and DIFFERENCE) is smaller than their short-run effects, suggesting that the respondents adapt to the level of happiness brought about with these variables.

Fourth, the absolute values of the estimates of the significant lagged variables of DIFFERENCE are larger than those of CHANGE in all cases, suggesting that adaptation is larger for DIFFERENCE than for CHANGE.

The fourth fact, which is the most important fact for this paper to determine, is the cause of the difference between CHANGE and DIFFERENCE (and thus between LEVEL and INTEG). In order to confirm the difference in the degree of adaptation between CHANGE and DIFFERENCE, we calculate the short-run effect, long-run effect, and adaptation ratio, which are defined as follows: the short-run effect is the coefficients of the current variables, the long-run effect is the sum of the significant coefficients of the current and lagged variables, and the adaptation ratio is defined as $\left(1-\frac{\text { long-run effect }}{\text { short-run effect }}\right) \times 100(\%)$. We do not calculate them if the coefficient of the current variable is insignificant (i.e., if the short-run effect is zero).

Table 4 presents the results. The adaptation ratios are close to $100 \%$ for all the variables for the case of DIFFERENCE for both waves, implying that none of the variables has any effect on happiness (DIFFERENCE, and therefore LEVEL) in the long-run. On the other hand, the adaptation ratios for CHANGE are approximately 50\% for the 2008-survey and approximately 
$30 \%$ for 2009-survey, suggesting that adaptation is not perfect for CHANGE.

The results suggest that the reason that the mean of DIFFERENCE is not statistically different from zero and $L E V E L$ fluctuates around a constant level is that the subjects fully adapt to the situation: although DIFFERENCE is significantly and largely affected by the current variables, the effect is cancelled in three days. In contrast, CHANGE also adapts to the situation; however, the adaptation is much weaker than that for DIFFERENCE. The difference in the magnitude of adaptation is the cause of the divergence between LEVEL and INTEG.

\section{Discussion and conclusions}

In this paper, we investigated whether the level of happiness and the integrated process of changes in happiness are the same process. We found that they follow different processes: although the level is stationary, the integration of changes is non-stationary with an apparent rising trend.

Despite the fact that mathematically, the integration of changes is the same as the level, why do these two variables diverge? We examined three possible reasons and found that DIFFERENCE is fully affected by adaptation, whereas CHANGE is partially affected by adaptation. Thus, in the long-run, the effects of various impacts on DIFFERENCE are completely cancelled in the following three days, whereas those on CHANGE are only partially 
cancelled. This is the reason why INTEG, which is the integration of CHANGE, and LEVEL, which is the integration of DIFFERENCE, diverge. Overall, the empirical outcomes are robust across the waves.

Our results have an important implication for the Easterlin paradox, which is the phenomenon that subjective happiness, which corresponds to LEVEL in this paper, is stable irrespective of whether the standard of living (GDP) improves or deteriorates. The relative income hypothesis and adaptation hypothesis are known to offer effective explanations of the paradox (Clark et al., 2008; Knight and Song, 2006), and they imply that if adaptation does not occur, the Easterlin paradox should, if not completely, partially disappear. Thus, our results suggest that if we ask about the change in happiness, CHANGE, and construct its integrated process, INTEG, then INTEG may not exhibit the Easterlin paradox. This inference is based on our results that adaptation affects CHANGE only partially, whereas it completely affects DIFFERENCE.

The relationship between subjective happiness and utility is not understood fully. ${ }^{22}$ We believe, however, that an important distinction between the two is that decision utility is constructed from comparisons of two ex-ante states, whereas subjective happiness is based on

\footnotetext{
${ }^{22}$ Many economists think that comparison of subjective happiness among individuals lacks a solid basis, whereas researchers in the field of economics of happiness estimate the happiness function using data on subjective happiness.
} 
the introspection of the current feelings of an individual. Since utility is based on a comparison of ex-ante states, it should be free from adaptation. Thus, utility is expected to increase when the standard of living (GDP) improves.

In fact, in a survey conducted in Japan in 2008, we asked respondents whether they would have preferred to have been born in 1910,1950 , or 1980 , and many selected the later period, suggesting that they preferred a higher standard of living when they compared the periods. We also asked Japanese respondents whether they would have preferred to have been born in Italy or Indonesia, and Singapore or Mexico. These two pairs of countries differ significantly with respect to GDP, but according to the World Value Survey, the average subjective happiness of the nations is almost the same. Most respondents chose Italy (84\%) and Singapore (68\%); both these countries enjoy higher GDPs.

The Easterlin paradox means that economic growth does not lead to an improvement in subjective happiness, which raises a question regarding the role of economic growth. However, our results suggest that INTEG (CHANGE) may be a closer concept to utility than LEVEL (DIFFERENCE) in that the former is freer from adaptation. This implies the possibility that the paradox will disappear if we measure subjective happiness by the sum of changes in happiness.

Let us examine the above speculation on the basis of our survey conducted in Japan from fiscal years 2003 to 2009. In the survey, we investigated the level of happiness (Q1) and the 
change in happiness compared with the level that existed a few years ago. From the former question, we defined $L E V E L$ as the average of the answer. In the latter question, respondents were requested to select from the following options: 1. Happier than a few years ago, 2. Same as a few years ago, 3. Unhappier than a few years ago. ${ }^{23}$ We defined CHANGE as two minus the answer to this question, which takes the value of 1,0 , or -1 . We used the average of CHANGE over all respondents and calculate INTEG as before. Figure 6 presents the values of $L E V E L$ and INTEG obtained subsequently. Although LEVEL is almost constant around 6.4, INTEG increases from 6.4 to 7.1, reflecting that CHANGE is positive for all the years. Thus, the result is essentially similar to those using the daily data in this paper. In the figure, we also show "consumption of household,” as a proxy for the standard of living, which seems to correspond more with INTEG than with LEVEL. ${ }^{24}$ Indeed, its correlation coefficient is -0.22 with $L E V E L$ and 0.74 with INTEG. These results suggest that the Easterlin paradox is seen between LEVEL and "consumption of household," but not between INTEG and “consumption of household." 25

A problem of this analysis is that the data spans only seven years. In order to obtain more

\footnotetext{
${ }^{23}$ To be precise, “4. Do not know" is included in the options. In 2008 and 2009, the comparison is made with “a year ago" instead of "a few years ago.”

${ }^{24}$ Here, "consumption of household" is normalized so that the value of the first year equals 6.38, that is, the value of $L E V E L$ in that year.

${ }^{25}$ When we use GDP instead of consumption of household, its coefficient is - 0.49 with LEVEL and 0.40 with INTEG.
} 
reliable results, it is necessary to conduct a longitudinal survey that investigates the changes in happiness and examines if the integrated process of the change in happiness corresponds to the standard of living (GDP). This is an important subject for future research. 


\section{Acknowledgments}

We would like to extend our heartfelt gratitude to Masahiko Shibamoto and Frans van Winden

for their comments and acknowledge financial support from the Global Center of Excellence

(GCOE) program at Osaka University. This paper was presented at MEW (Monetary Economics

Workshop) and the 2011 Spring Meeting of the Japanese Economic Association. 


\section{References}

Bruni, L. and P. L. Porta (2005) Economics and Happiness: Framing the Analysis, New York: Oxford University Press.

Choi, I. (2001) "Unit Root Tests for Panel Data”, Journal of International Money and Finance, Vol. 20, No. 2, pp. 249-272.

Clark, A. E., P. Frijters and M. A. Shields (2008) "Relative Income, Happiness, and Utility: An Explanation for the Easterlin Paradox and Other Puzzles", Journal of Economic Literature, Vol. 46, No. 1, pp. 95-144.

Clark, A. E. and A. J. Oswald (1996) "Satisfaction and Comparison Income”, Journal of Public Economics, Vol. 61, No. 3, pp. 359-81.

Csikszentmihalyi, M. and J. Hunter (2003) "Happiness in Everyday Life: The Uses of Experience Sampling”, Journal of Happiness Studies, Vol. 4, pp. 185-199.

Dickey, D. A. and W. A. Fuller (1979) "Distribution of the Estimators for Autoregressive Time Series with a Unit Root”, Journal of the American Statistical Association, Vol. 74, No. 366, pp. 427-431.

Di Tella, R., J. Haisken-DeNew and R. J. MacCulloch (2007) "Happiness Adaptation to Income and to Status in an Individual Panel”, NBER Working Paper, No. 13159.

Dolan, P., T. Peasgood, and M. White (2008) “Do We Really Know What Makes Us Happy? A Review of the Economic Literature on the Factors Associated with Subjective Well-being”, Journal of Economic Psychology, Vol. 29, No. 1, pp. 94-122.

Duesenberry, J. S. (1949) Income, Savings, and the Theory of Consumer Behaviour, Cambridge: Harvard University Press.

Easterlin, R. A. (1974) "Does Economic Growth Improve the Human Lot? Some Empirical Evidence", in P. A. David and M. W. Reder, eds., Nations and Households in Economic Growth: Essays in Honor of Moses Abramowitz, New York: Academic Press, pp. 89-125. (2005) "Building a Better Theory of Well-Being”, in L. Bruni and P. L. Porta, eds., Economics and Happiness, Oxford: Oxford University Press, pp. 29-64. 
Frank, R. H. (2005) “Does Absolute Income Matter?” in L. Bruni and P. L. Porta, eds., Economics and Happiness, Oxford: Oxford University Press, pp. 65-90.

Frey, B. S. and A. Stutzer (2002a) Happiness and Economics, Princeton: Princeton University Press. and ___ (2002b) "What Can Economists Learn from Happiness Research?” Journal of Economic Literature, Vol. 40, No. 2, pp. 402-435.

Kahneman, D. and A. B. Krueger (2006) "Developments in the Measurement of Subjective Well-Being”, Journal of Economic Perspectives, Vol. 20, No. 1, pp. 3-24.

Kahneman, D., A. B. Krueger, D. Schkade, N. Schwartz and A. A. Stone (2004a) “A Survey Method for Characterizing Daily Life Experience: The Day Reconstruction Method”, Science, Vol. 306, pp. 1776-1780.

and (2004b) “Toward National Well-Being Accounts”, AEA

Papers and Proceedings, pp. 429-439.

Kahneman, D. and A. Tversky (1979) "Prospect Theory: An Analysis of Decision Making under Risk”, Econometrica, Vol. 47, No. 2, pp. 263-292.

Kimball, M. and R. Willis (2006) “Utility and Happiness”, mimeo.

Knight, J. and L. Song (2006) "Subjective Well-Being and Its Determinants in Rural China”, http://www.economics.ox.ac.uk/Research/wp/pdf/paper334.pdf.

Kwiatkowski, D., P. C. B. Phillips, P. Schmidt and Y. Shin (1992) “Testing the Null Hypothesis of Stationarity against the Alternative of a Unit Root: How Sure Are We That Economic Time Series Have a Unit Root?” Journal of Econometrics, Vol. 54, Nos. 1-3, pp. 159-178.

Scollon, C. N., C. Kim-Prieto and E. Diener (2003) "Experience Sampling: Promises and Pitfalls, Strengths and Weaknesses”, Journal of Happiness Studies, Vol. 4, pp. 5-34. 
Stevenson, B. and J. Wolfers (2008) "Economic Growth and Subjective Well-being: Reassessing the Easterlin Paradox”, Brookings Papers on Economic Activity, Spring, pp. $1-102$.

Tversky, A. and D. Kahneman (1992) "Advances in Prospect Theory: Cumulative Representation of Uncertainty”, Journal of Risk and Uncertainty, Vol. 5, No. 4, pp. 297-323. 
Table1 Descriptive statistics

\begin{tabular}{|c|c|c|c|c|c|c|c|}
\hline 2008-survey & Mean & $\begin{array}{l}\text { Standard } \\
\text { Deviation }\end{array}$ & $\begin{array}{r}\text { standard } \\
\text { error }\end{array}$ & $\begin{array}{r}95 \% \text { lower } \\
\text { band }\end{array}$ & $\begin{array}{r}95 \% \text { upper } \\
\text { band }\end{array}$ & Min. & Max. \\
\hline LEVEL & 5.875 & 2.036 & 0.024 & 5.829 & 5.922 & 0 & 10 \\
\hline CHANGE & 0.115 & 1.223 & 0.014 & 0.088 & 0.143 & -3 & 3 \\
\hline INTEG & 10.585 & 40.639 & 0.473 & 9.659 & 11.512 & -151 & 347 \\
\hline DIFFERENCE & 0.003 & 1.656 & 0.019 & -0.035 & 0.041 & -10 & 10 \\
\hline$P_{-} N E W S$ & 0.544 & 2.297 & 0.027 & 0.492 & 0.597 & -5 & 5 \\
\hline M_NEWS & -0.4 & 1.981 & 0.023 & -0.445 & -0.354 & -5 & 5 \\
\hline$S L E E P$ & 2.645 & 0.984 & 0.011 & 2.622 & 2.667 & 1 & 4 \\
\hline HEALTH & 2.737 & 0.813 & 0.009 & 2.718 & 2.756 & 1 & 4 \\
\hline NOANXIEY & 2.021 & 0.952 & 0.011 & 1.999 & 2.043 & 1 & 4 \\
\hline NOCLASS & 0.684 & 0.465 & 0.005 & 0.673 & 0.695 & 0 & 1 \\
\hline $\begin{array}{l}\text { Number of } \\
\text { observations }\end{array}$ & 7389 & & & & & & \\
\hline 2009-survey & Mean & $\begin{array}{l}\text { Standard } \\
\text { Deviation }\end{array}$ & $\begin{array}{r}\text { standard } \\
\text { error }\end{array}$ & $\begin{array}{r}95 \% \text { lower } \\
\text { band }\end{array}$ & $\begin{array}{r}95 \% \text { upper } \\
\text { band }\end{array}$ & Min. & Max. \\
\hline LEVEL & 6.216 & 2.036 & 0.024 & 6.170 & 6.263 & 0 & 10 \\
\hline CHANGE & 0.199 & 1.141 & 0.013 & 0.173 & 0.225 & -3 & 3 \\
\hline INTEG & 23.836 & 56.939 & 0.666 & 22.531 & 25.140 & -167 & 476 \\
\hline DIFFERENCE & -0.003 & 1.573 & 0.018 & -0.039 & 0.033 & -9 & 10 \\
\hline P_NEWS & 0.794 & 2.577 & 0.030 & 0.735 & 0.853 & -5 & 5 \\
\hline M_NEWS & -0.064 & 2.068 & 0.024 & -0.112 & -0.017 & -5 & 5 \\
\hline$S L E E P$ & 2.652 & 0.988 & 0.012 & 2.629 & 2.674 & 1 & 4 \\
\hline HEALTH & 2.817 & 0.872 & 0.010 & 2.797 & 2.837 & 1 & 4 \\
\hline NOANXIEY & 2.271 & 1.061 & 0.012 & 2.247 & 2.295 & 1 & 4 \\
\hline NOCLASS & 0.580 & 0.494 & 0.006 & 0.569 & 0.591 & 0 & 1 \\
\hline $\begin{array}{l}\text { Number of } \\
\text { observations }\end{array}$ & 7319 & & & & & & \\
\hline
\end{tabular}


Table 2 Results of panel unit root tests

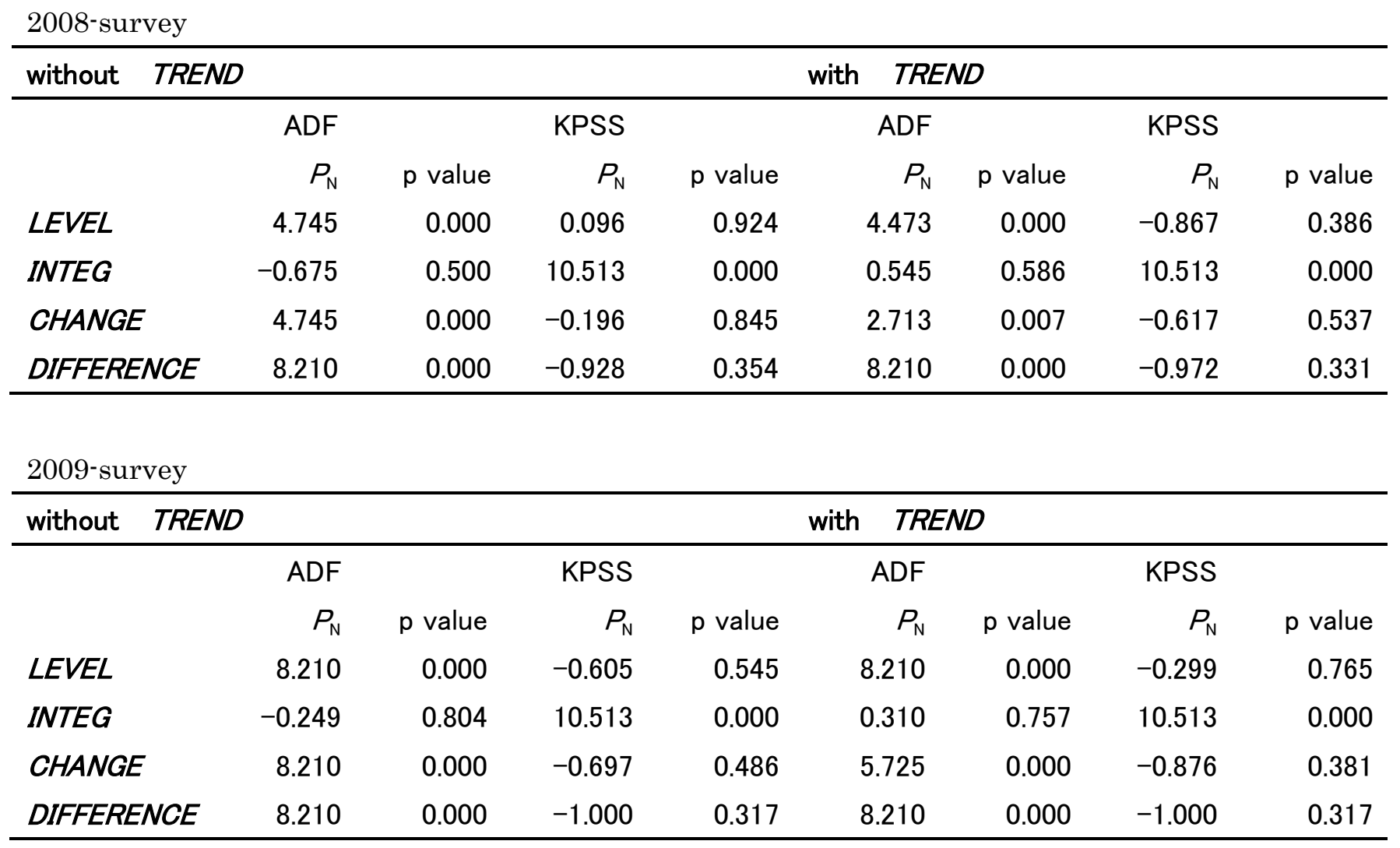

Note: $P_{\mathrm{N}}$ is a Fisher's statistic as defined in Choi (2001) based on a p value of the individual augmented Dickey and Fuller (1979) of null of a unit root and the individual Kwiatkowski et al. (1992) test of the null of no unit root. The lag length of the lagged difference terms to be added to the individual ADF test was selected according to Akaike information criterion (AIC) for each regression, and truncation lags in the KPSS test was set at 12. A Fisher's statistic $P_{\mathrm{N}}$ as defined in Choi $(2001)$ has a $N(0,1)$ distribution under the null hypothesis. 
Table 3 Estimation results on adaptation hypothesis

\begin{tabular}{|c|c|c|c|c|}
\hline \multirow[b]{4}{*}{ Variable } & \multicolumn{2}{|l|}{2008} & & \\
\hline & \multirow{2}{*}{\multicolumn{2}{|c|}{$\begin{array}{l}\text { CHANGE } \\
\text { fixed effect }\end{array}$}} & \multirow{2}{*}{\multicolumn{2}{|c|}{$\begin{array}{l}\text { DIFFERENCE } \\
\text { random effect }\end{array}$}} \\
\hline & & & & \\
\hline & Coefficient & $\mathrm{P}$-value & Coefficient & $\mathrm{P}$-value \\
\hline P_NEWS & 0.302 & {$[.000]$} & 0.404 & {$[.000]$} \\
\hline$P_{-} N E W S(-1)$ & -0.084 & {$[.000]$} & -0.363 & {$[.000]$} \\
\hline$P_{-} N E W S(-2)$ & -0.039 & {$[.000]$} & -0.033 & {$[.000]$} \\
\hline$P_{-} N E W S(-3)$ & -0.025 & {$[.000]$} & -0.011 & [.165] \\
\hline M_NEWS & 0.007 & {$[.250]$} & 0.050 & {$[.000]$} \\
\hline M_NEWS(-1) & -0.009 & {$[.174]$} & -0.052 & {$[.000]$} \\
\hline M_NEWS(-2) & -0.011 & {$[.091]$} & 0.001 & [.889] \\
\hline M_NEWS(-3) & -0.020 & {$[.002]$} & -0.001 & [.918] \\
\hline SLEEP & 0.000 & {$[.999]$} & 0.020 & [.311] \\
\hline$S L E E P(-1)$ & -0.033 & {$[.013]$} & -0.008 & [.704] \\
\hline$S L E E P(-2)$ & 0.011 & [.418] & 0.013 & [.525] \\
\hline$S L E E P(-3)$ & 0.005 & {$[.680]$} & -0.027 & [.162] \\
\hline$H E A L T H$ & 0.179 & {$[.000]$} & 0.206 & {$[.000]$} \\
\hline$H E A L T H(-1)$ & -0.047 & {$[.011]$} & -0.165 & {$[.000]$} \\
\hline$H E A L T H(-2)$ & -0.035 & {$[.061]$} & 0.006 & [.827] \\
\hline$H E A L T H(-3)$ & -0.038 & {$[.037]$} & -0.053 & {$[.046]$} \\
\hline NOANXIETY & 0.293 & {$[.000]$} & 0.187 & {$[.000]$} \\
\hline NOANXIETY(-1) & -0.087 & {$[.000]$} & -0.166 & {$[.000]$} \\
\hline NOANXIETY(-2) & -0.020 & {$[.284]$} & 0.026 & [.348] \\
\hline NOANXIETY(-3) & -0.064 & {$[.000]$} & -0.039 & [.142] \\
\hline NOCLASS & 0.078 & {$[.004]$} & 0.034 & [.394] \\
\hline NOCLASS(-1) & -0.035 & {$[.227]$} & -0.093 & {$[.034]$} \\
\hline NOCLASS(-2) & -0.039 & [.173] & -0.010 & [.823] \\
\hline NOCLASS(-3) & -0.016 & {$[.541]$} & 0.030 & [.459] \\
\hline constant & & & 0.036 & [.637] \\
\hline adjusted $\mathrm{R}^{2}$ & 0.535 & & 0.392 & \\
\hline Number of & 7249 & & 7249 & \\
\hline observations & & & & \\
\hline Hausman test & & {$[.027]$} & & {$[1.000]$} \\
\hline
\end{tabular}




\begin{tabular}{|c|c|c|c|c|}
\hline \multirow[b]{3}{*}{ Variable } & \multicolumn{2}{|l|}{2009} & \multirow{2}{*}{\multicolumn{2}{|c|}{$\begin{array}{l}\text { DIFFERENCE } \\
\text { random effect }\end{array}$}} \\
\hline & $\begin{array}{l}\text { CHANGE } \\
\text { random effe }\end{array}$ & & & \\
\hline & Coefficient & $\mathrm{P}$-value & Coefficient & $\mathrm{P}$-value \\
\hline P_NEWS & 0.260 & {$[.000]$} & 0.295 & {$[.000]$} \\
\hline$P_{-} N E W S(-1)$ & -0.050 & {$[.000]$} & -0.274 & {$[.000]$} \\
\hline$P_{-} N E W S(-2)$ & -0.023 & {$[.000]$} & -0.019 & {$[.015]$} \\
\hline$P_{-} N E W S(-3)$ & -0.015 & {$[.001]$} & -0.011 & [.129] \\
\hline M_NEWS & 0.047 & {$[.000]$} & 0.045 & {$[.000]$} \\
\hline$M \_N E W S(-1)$ & -0.017 & {$[.001]$} & -0.042 & {$[.000]$} \\
\hline$M \_N E W S(-2)$ & 0.004 & {$[.405]$} & 0.004 & [.622] \\
\hline M_NEWS(-3) & 0.000 & {$[.978]$} & -0.003 & [.684] \\
\hline SLEEP & 0.036 & {$[.001]$} & 0.001 & [.959] \\
\hline$S L E E P(-1)$ & 0.011 & {$[.351]$} & 0.015 & [.420] \\
\hline$S L E E P(-2)$ & -0.014 & {$[.210]$} & -0.038 & [.041] \\
\hline$S L E E P(-3)$ & 0.006 & {$[.601]$} & 0.024 & [.182] \\
\hline$H E A L T H$ & 0.172 & {$[.000]$} & 0.174 & {$[.000]$} \\
\hline$H E A L T H(-1)$ & -0.048 & {$[.006]$} & -0.176 & {$[.000]$} \\
\hline$H E A L T H(-2)$ & -0.014 & [.404] & 0.008 & [.773] \\
\hline$H E A L T H(-3)$ & -0.012 & {$[.466]$} & -0.003 & [.923] \\
\hline NOANXIETY & 0.228 & {$[.000]$} & 0.288 & {$[.000]$} \\
\hline NOANXIETY(-1) & -0.059 & {$[.000]$} & -0.301 & {$[.000]$} \\
\hline NOANXIETY(-2) & -0.021 & [.191] & 0.043 & [.106] \\
\hline NOANXIETY(-3) & -0.052 & {$[.001]$} & -0.036 & [.163] \\
\hline NOCLASS & 0.055 & {$[.016]$} & 0.008 & [.838] \\
\hline NOCLASS(-1) & -0.038 & [.119] & -0.076 & {$[.061]$} \\
\hline NOCLASS(-2) & -0.001 & {$[.969]$} & 0.059 & [.145] \\
\hline NOCLASS(-3) & 0.016 & [.489] & -0.015 & [.689] \\
\hline constant & -0.564 & {$[.000]$} & 0.018 & [.812] \\
\hline adjusted $\mathrm{R}^{2}$ & 0.445 & & 0.311 & \\
\hline $\begin{array}{l}\text { Number of } \\
\text { observations }\end{array}$ & 7211 & & 7211 & \\
\hline Hausman test & & [.532] & & [1.000] \\
\hline
\end{tabular}


Table 4 Adaptation ratio of $C H A N G E$ and DIFFERENCE

\begin{tabular}{|c|c|c|c|c|c|}
\hline & & 2008 & & 2009 & \\
\hline & & CHANGE & DIFFERENCE & CHANGE & DIFFERENCE \\
\hline \multirow[t]{3}{*}{ P_NEWS } & short-run effect & 0.302 & 0.404 & 0.260 & 0.295 \\
\hline & long-run effect & 0.153 & -0.003 & 0.172 & 0.003 \\
\hline & adaptation ratio (\%) & 49.3 & 100.8 & 34.1 & 99.1 \\
\hline \multirow[t]{3}{*}{ M_NEWS } & short-run effect & 0 & 0.050 & 0.047 & 0.045 \\
\hline & long-run effect & NA & -0.003 & 0.030 & 0.003 \\
\hline & adaptation ratio $(\%)$ & NA & 105.2 & 36.0 & 93.2 \\
\hline \multirow[t]{3}{*}{$S L E E P$} & short-run effect & 0 & 0 & 0.036 & 0 \\
\hline & long-run effect & NA & NA & 0.036 & NA \\
\hline & adaptation ratio (\%) & NA & NA & 0.0 & NA \\
\hline \multirow[t]{3}{*}{$H E A L T H$} & short-run effect & 0.179 & 0.206 & 0.172 & 0.174 \\
\hline & long-run effect & 0.094 & -0.012 & 0.125 & -0.002 \\
\hline & adaptation ratio (\%) & 47.6 & 105.7 & 27.6 & 101.1 \\
\hline \multirow[t]{3}{*}{ ANXIETY } & short-run effect & 0.293 & 0.187 & 0.228 & 0.288 \\
\hline & long-run effect & 0.143 & 0.021 & 0.117 & -0.012 \\
\hline & adaptation ratio $(\%)$ & 51.4 & 88.8 & 48.6 & 104.2 \\
\hline \multirow[t]{3}{*}{ NOCLASS } & short-run effect & 0.078 & 0 & 0 & 0 \\
\hline & long-run effect & 0.078 & NA & NA & NA \\
\hline & adaptation ratio (\%) & 0.0 & NA & NA & NA \\
\hline
\end{tabular}


Figure 1 Response rate

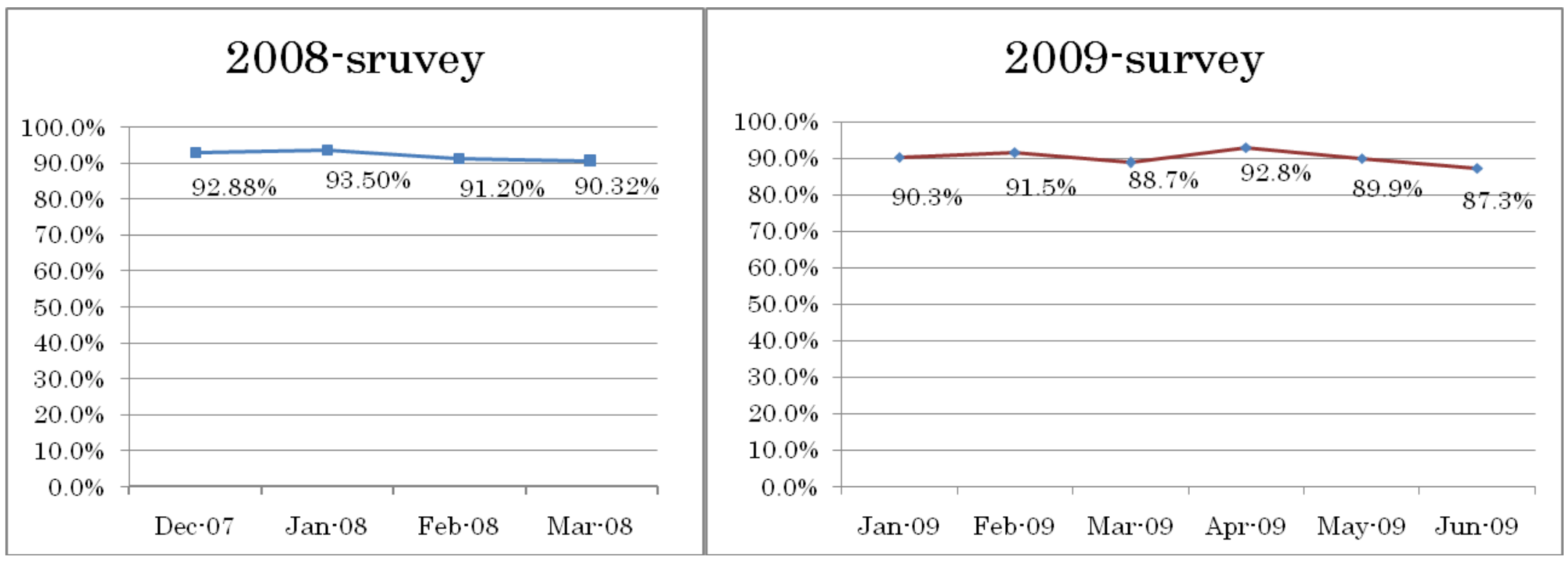


Figure 2 LEVEL and INTEG

2008-survey

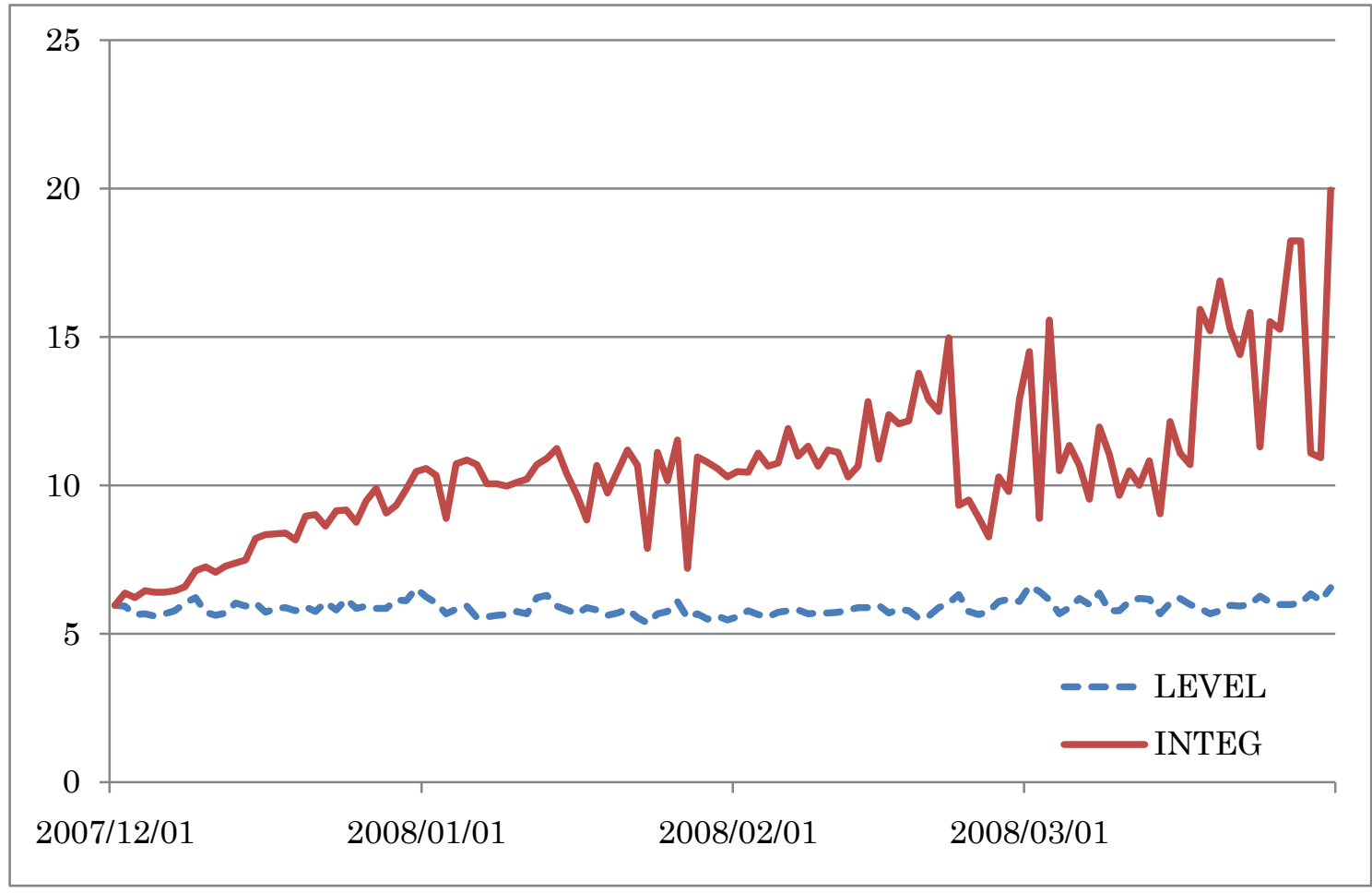

2009-survey

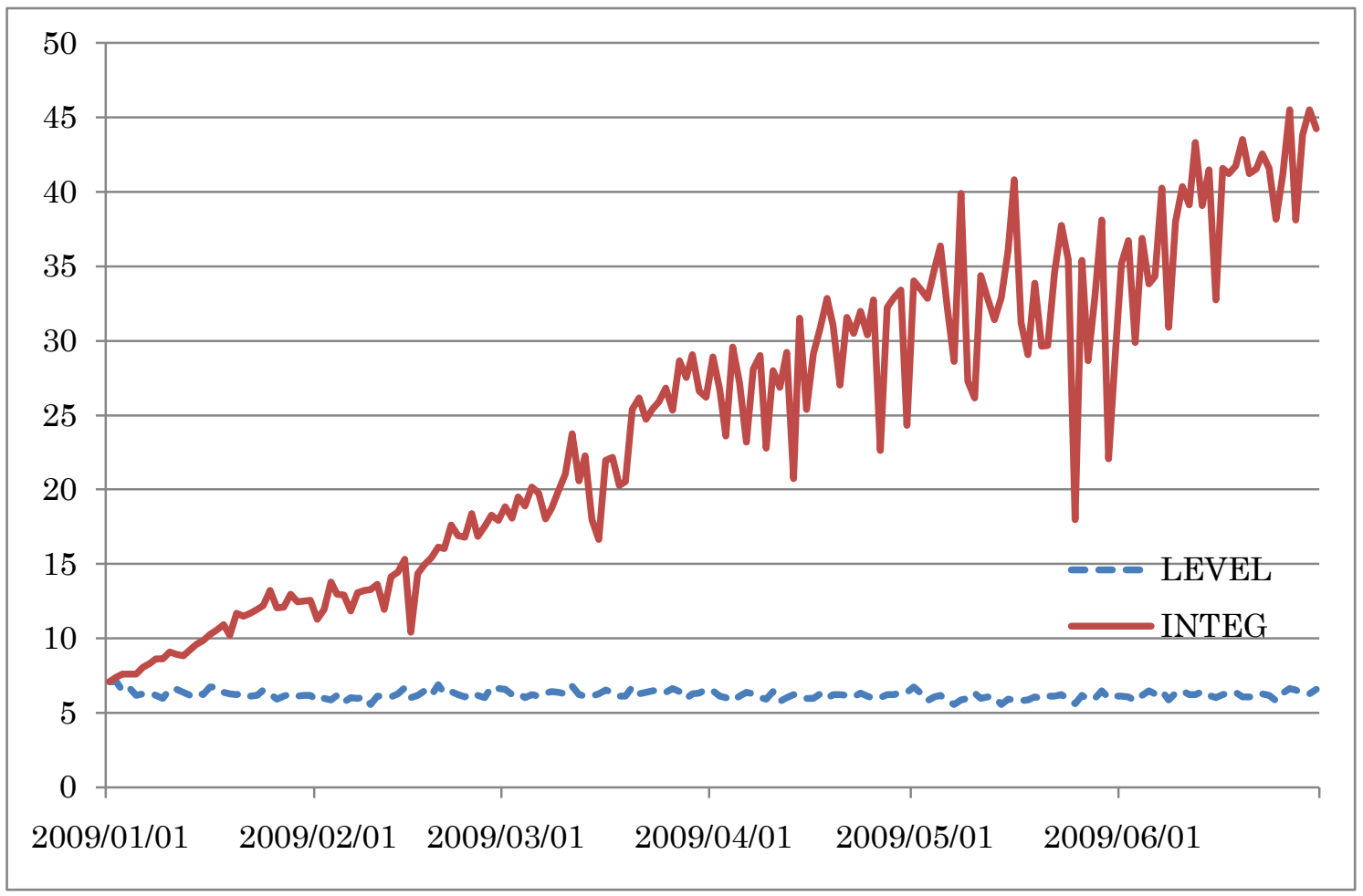


Figure3 CHANGE and DIFFERENCE

2008-survey

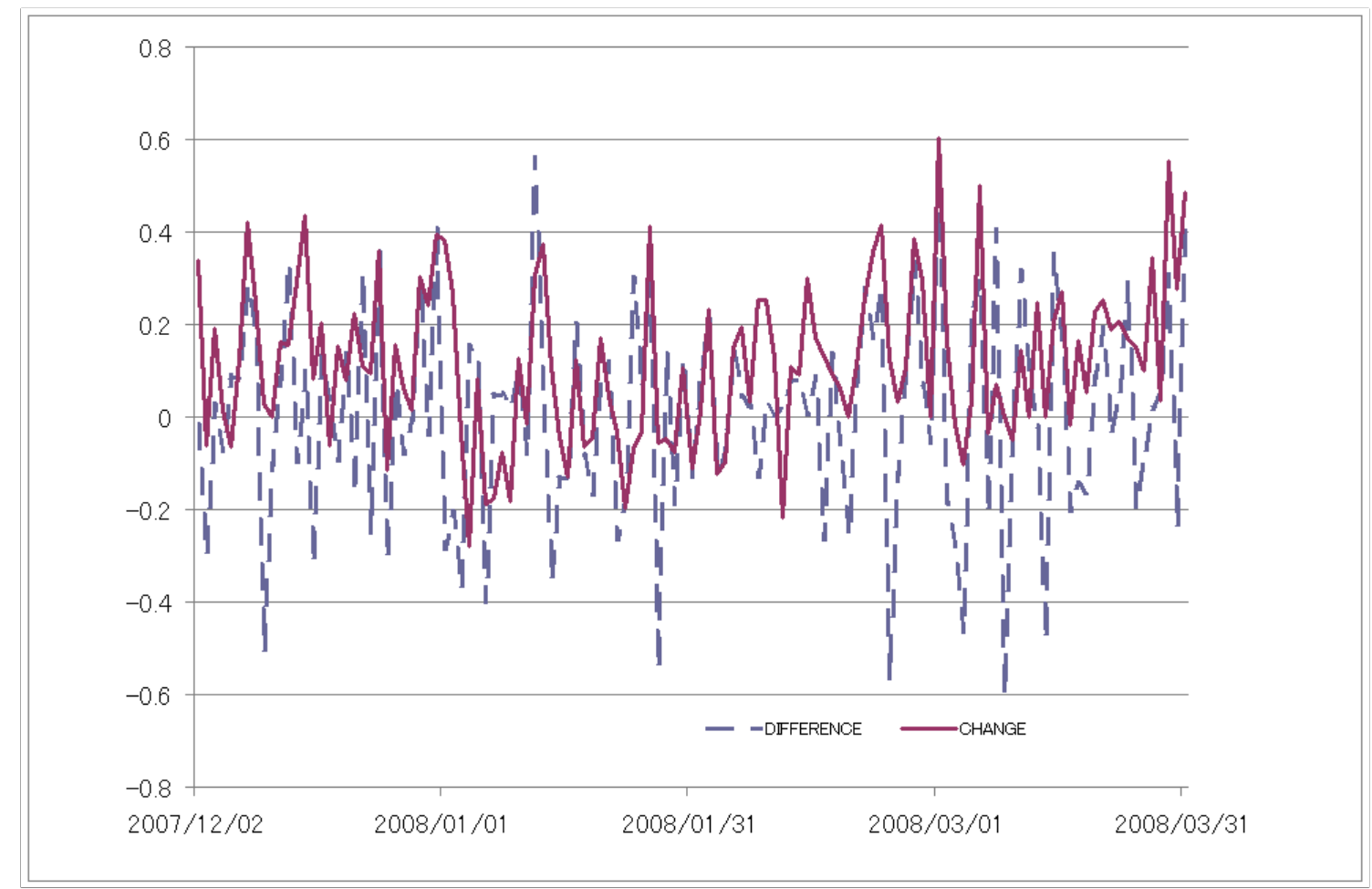

2009-survey

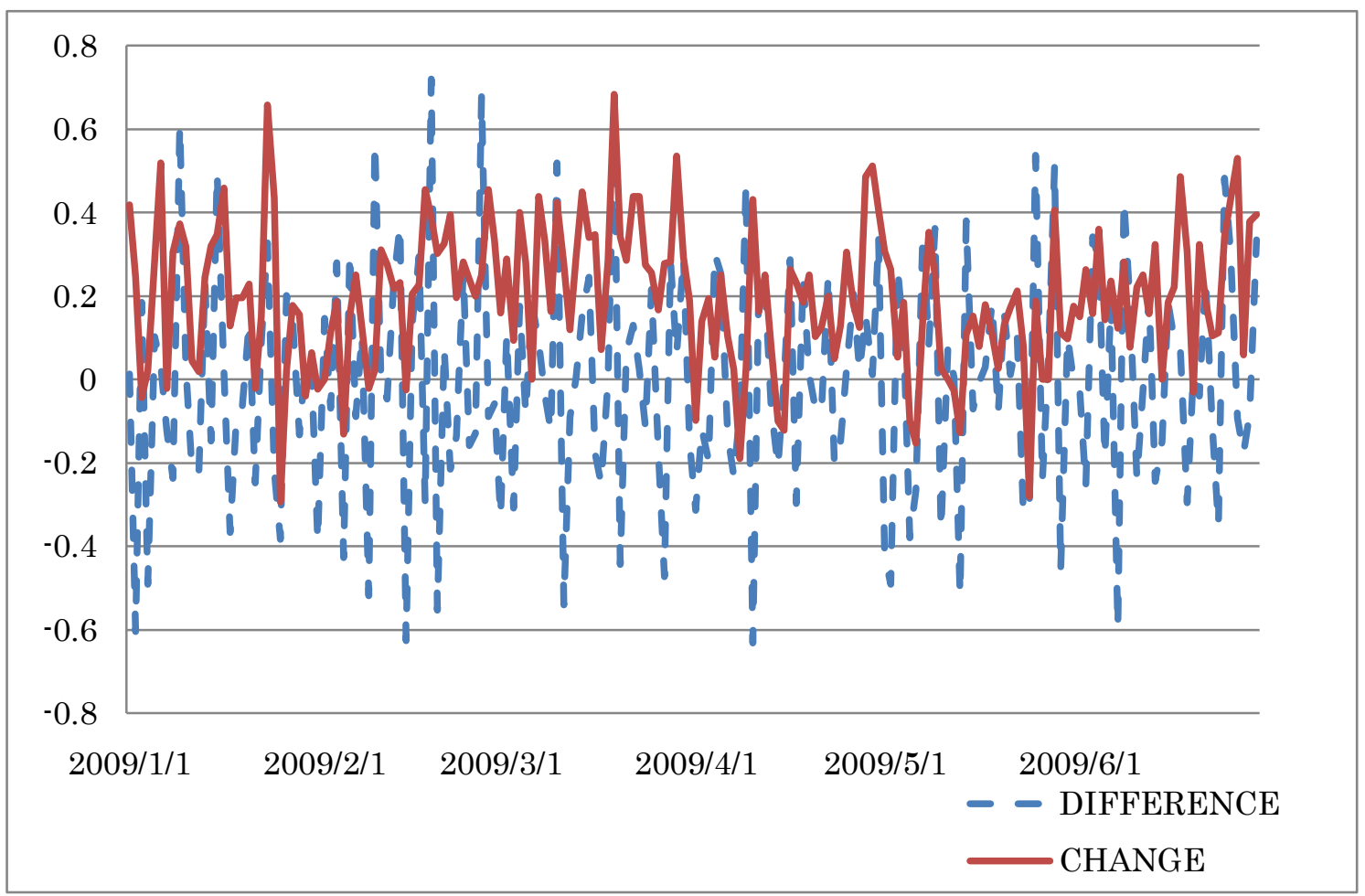


Figure 4 Recovered $\widetilde{H}$ using equation (3)

2008-survey

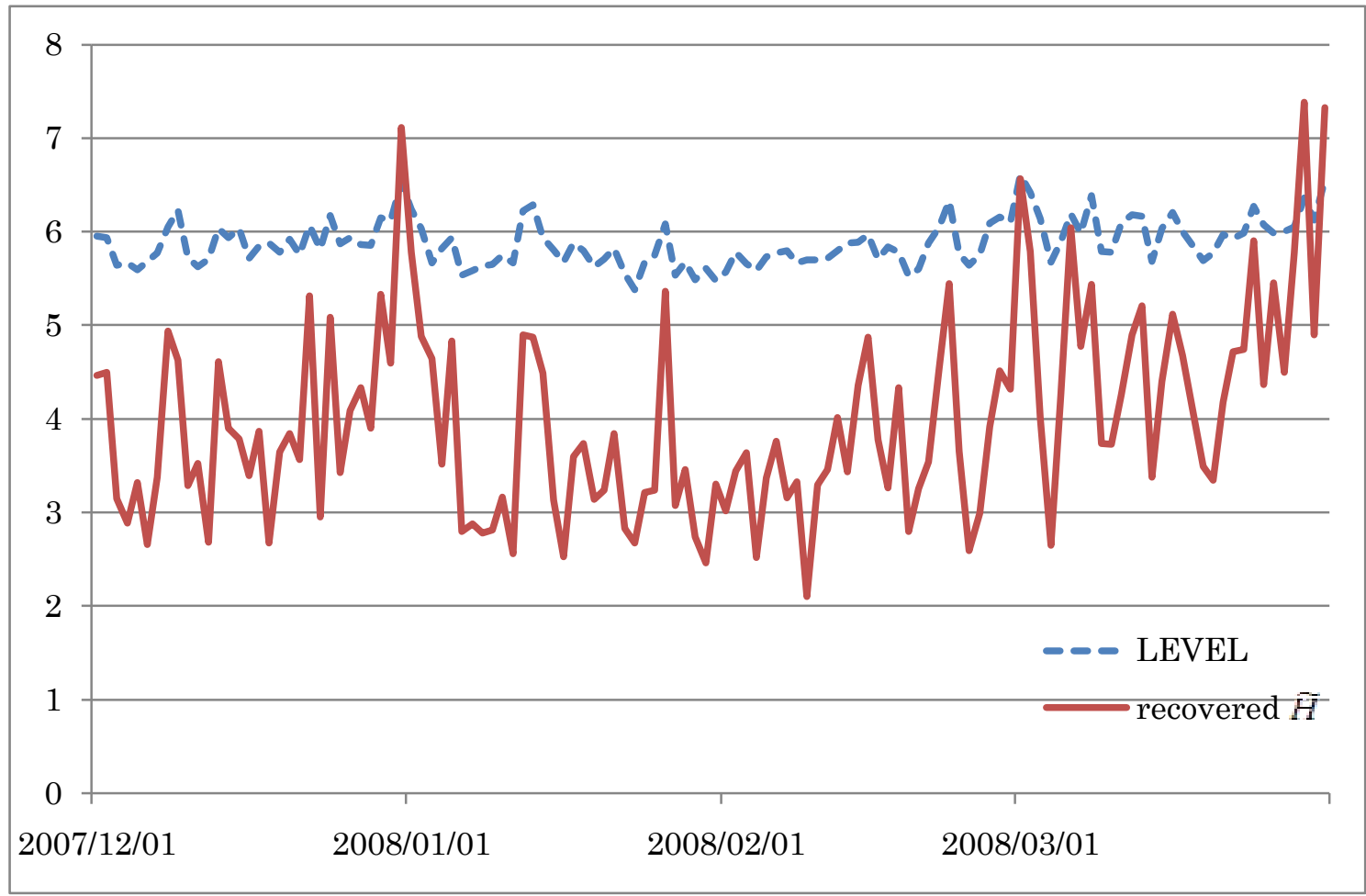

2009-survey

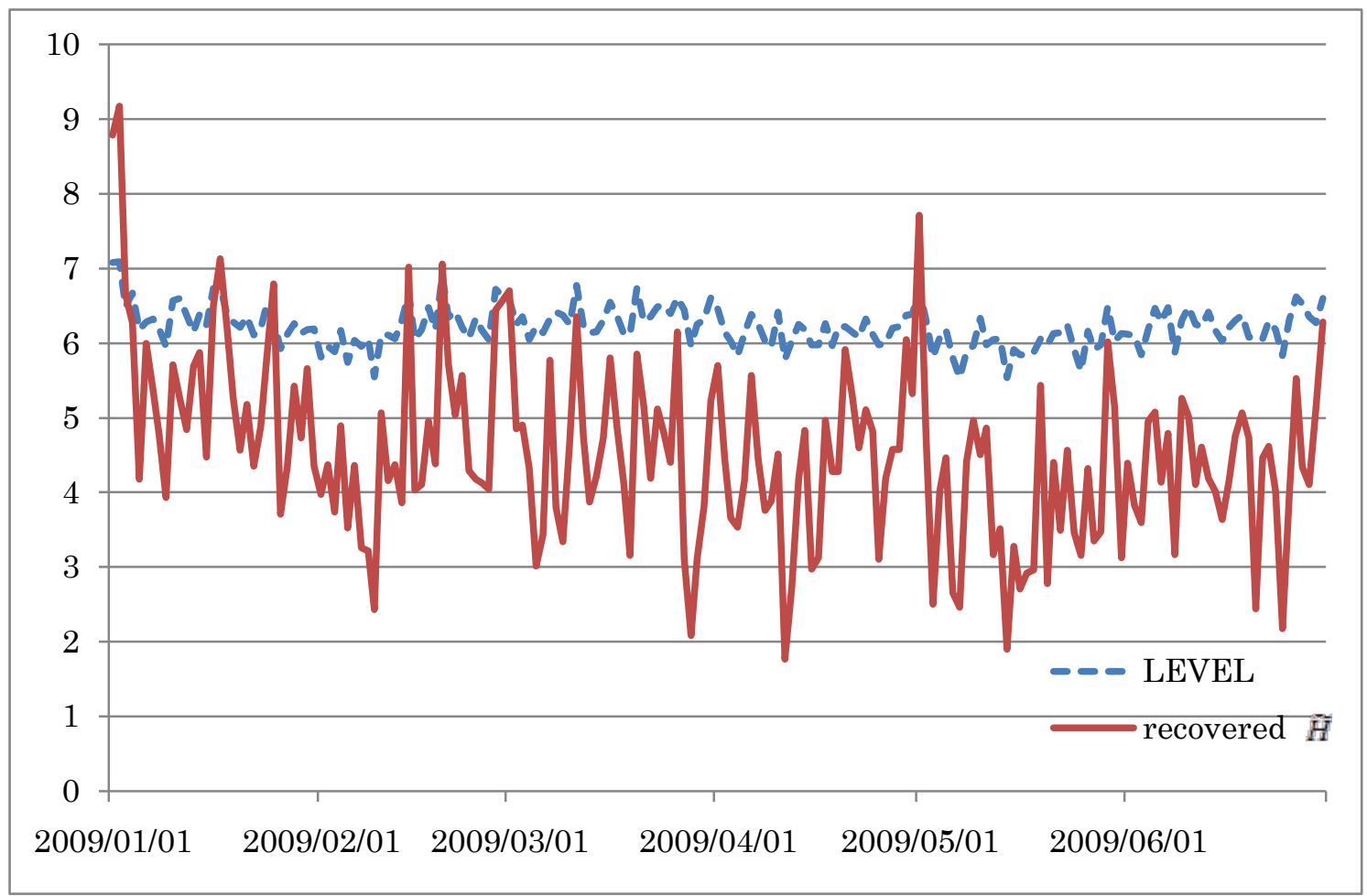


Figure 5 Latent happiness

2008-survey

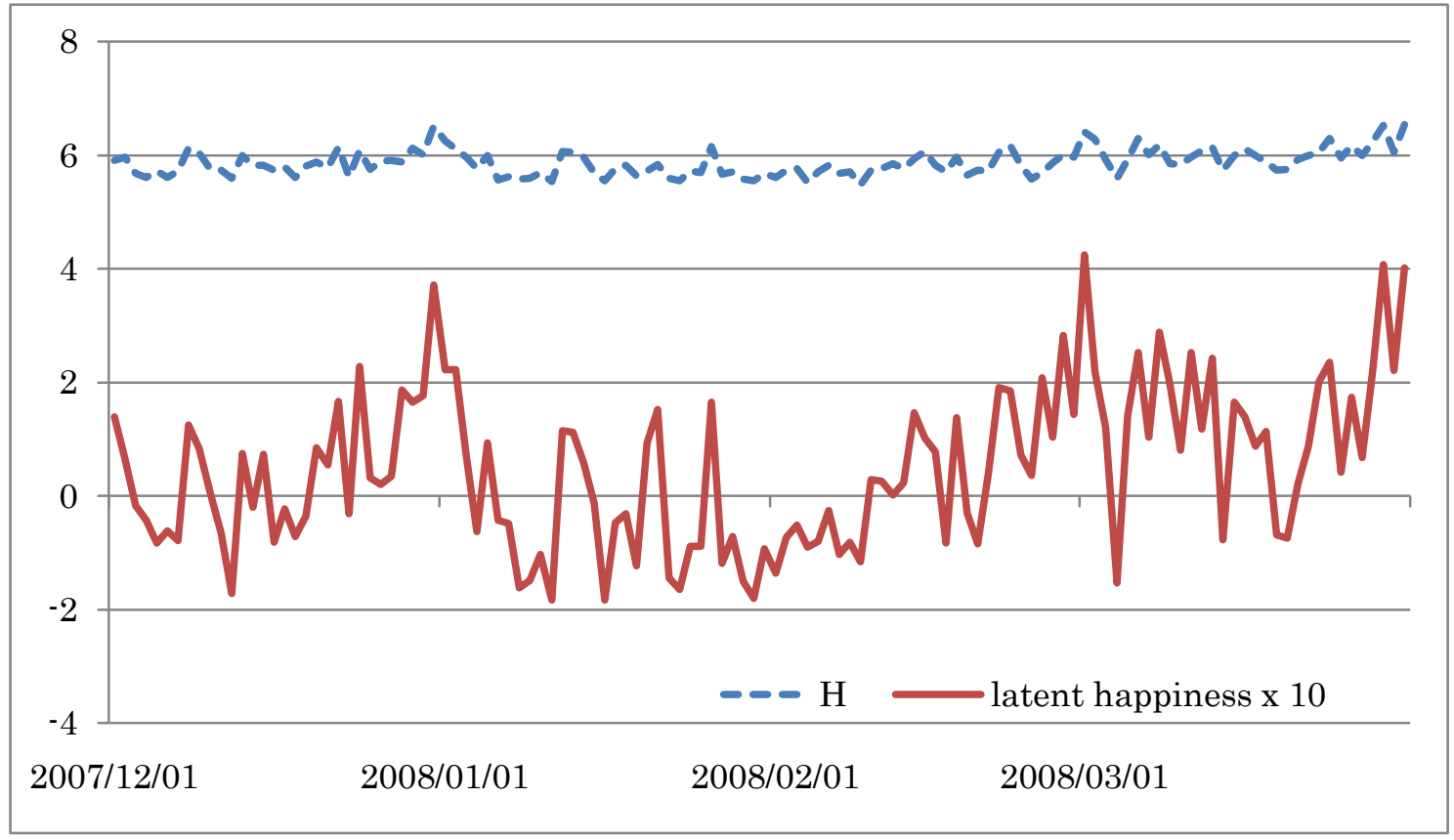

2009-survey

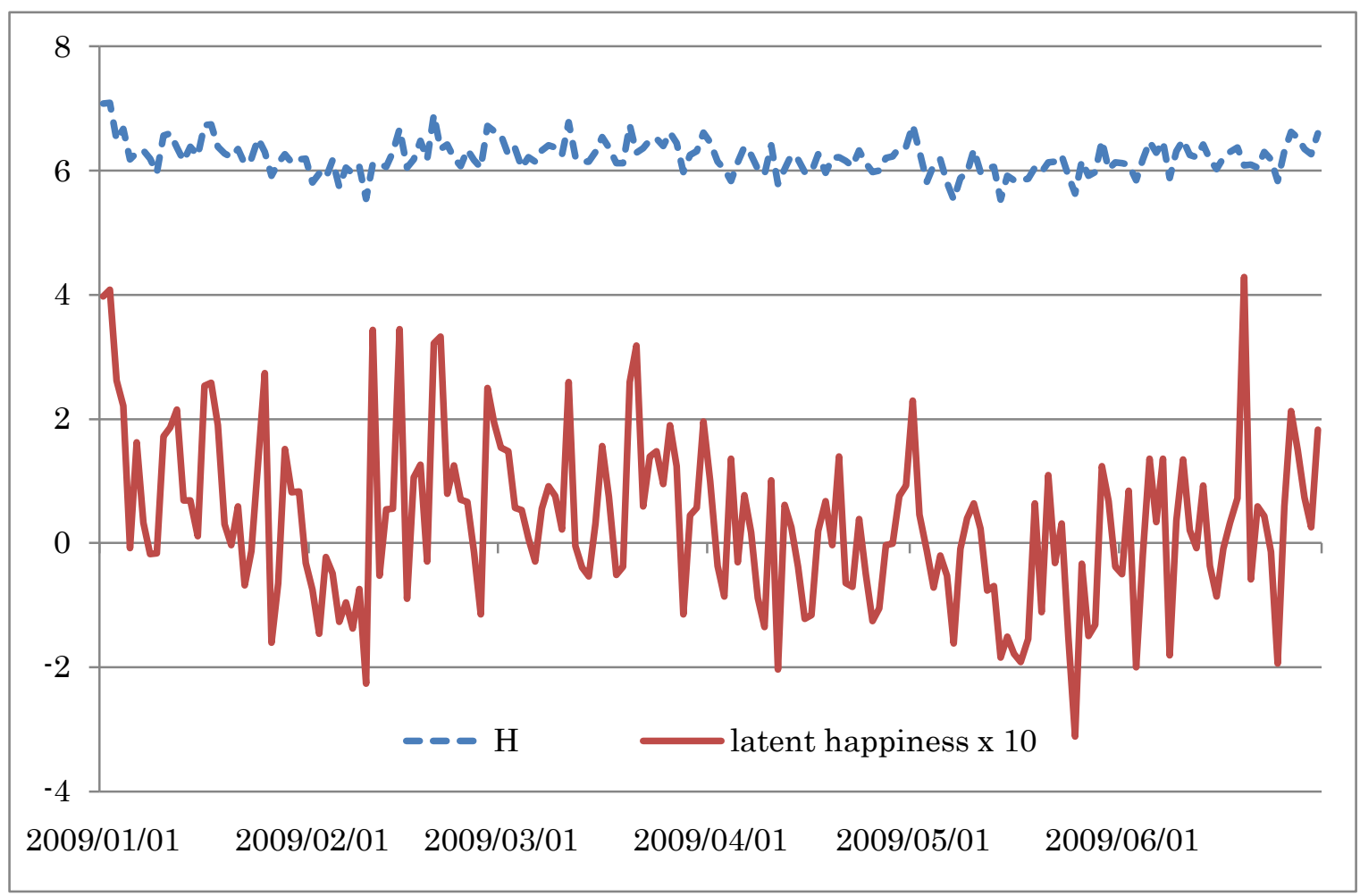


Figure 6 The Easterlin paradox

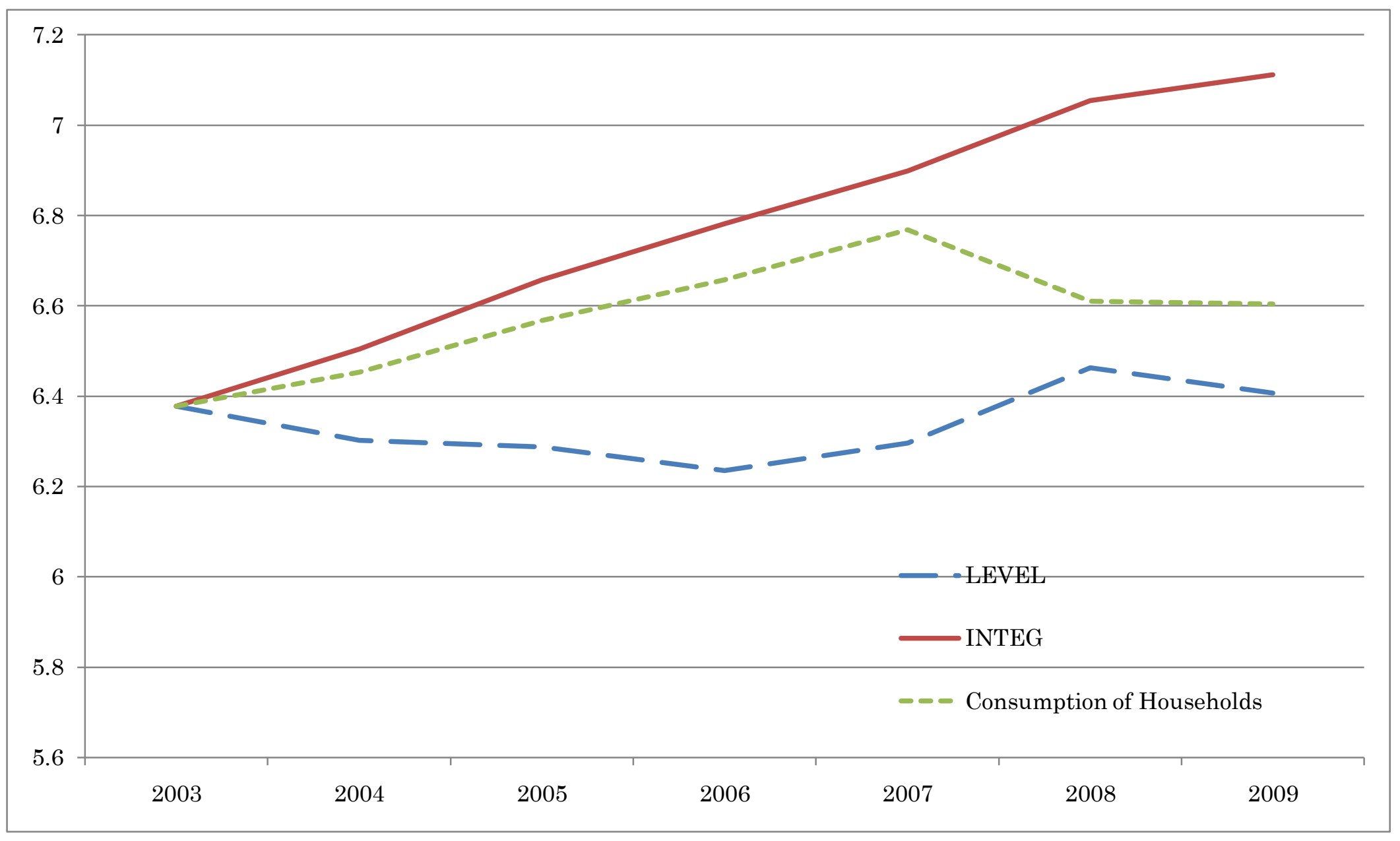

